\title{
Sarcopenia in gastric cancer: when the loss costs too much
}

\author{
Elena Ongaro $^{1} \cdot$ Vanessa Buoro $^{1} \cdot$ Marika Cinausero $^{1} \cdot$ Riccardo Caccialanza $^{2} \cdot$ \\ Annalisa Turri ${ }^{2}$ - Valentina Fanotto ${ }^{1}$. Debora Basile ${ }^{1} \cdot$ Maria Grazia Vitale $^{1}$. \\ Paola Ermacora $^{1}$ - Giovanni Gerardo Cardellino ${ }^{1} \cdot$ Laura Nicoletti $^{3}$. \\ Lorenzo Fornaro $^{4} \cdot$ Andrea Casadei-Gardini $^{5} \cdot$ Giuseppe Aprile $^{1,3}$
}

Received: 9 February 2017/Accepted: 23 April 2017/Published online: 5 May 2017

(c) The International Gastric Cancer Association and The Japanese Gastric Cancer Association 2017

\begin{abstract}
Sarcopenia is a complex syndrome characterized by progressive and generalized loss of skeletal muscle mass and strength. Malignancy is a major determinant of sarcopenia, and gastric cancer (GC) is among the most common causes of this phenomenon. As sarcopenia is a well-recognized poor prognostic feature in GC and has been associated with worse tolerance of surgical and medical treatments, members of the multidisciplinary team should be aware of the clinical relevance, pathogenic mechanisms, and potential treatments for this syndrome. The importance of sarcopenia is often underestimated in everyday practice and clinical trials, particularly among elderly or fragile patients. As treatment options are improving in all disease stages, deeper knowledge and greater attention to the metabolic balance in GC patients could further increase the benefit of novel therapeutic strategies and dramatically impact on quality of life. In this review, we describe the role of sarcopenia in different phases of GC progression. Our aim is to provide
\end{abstract}

Giuseppe Aprile

giuseppe.aprile@aulss8.veneto.it

1 Department of Oncology, University and General Hospital, Udine, Italy

2 Clinical Nutrition Service, Fondazione IRCCS Policlinico San Matteo, Pavia, Italy

3 Department of Oncology, San Bortolo General Hospital, Azienda ULSS8 Berica, East District, Viale Rodolfi 37, 36100 Vicenza, Italy

4 Medical Oncology 2, Azienda Ospedaliero-Universitaria Pisana, University of Pisa, Pisa, Italy

5 Department of Medical Oncology, Istituto Scientifico Romagnolo per lo Studio e la Cura dei Tumori, Meldola, FC, Italy oncologists and surgeons dealing with GC patients with a useful tool for comprehensive assessment and timely management of this potentially life-threatening condition.

Keywords Sarcopenia - Gastric cancer · Nutritional assessment $\cdot$ Malnutrition $\cdot$ Weight loss

\section{Introduction}

Gastric cancer (GC) is the fifth most common cancer and the third leading cause of cancer death worldwide [1]. Despite some improvements, GC prognosis is still poor, with surgical resection remaining the most effective therapy for potentially curable GC. However, as the population ages and an increasing number of older patients requires complex gastrointestinal surgical procedures, gastrectomy is associated with higher complication and postoperative mortality rates [2], while the underpinning cancer may promote muscle atrophy, particularly in the elderly.

The definition of sarcopenia encompasses decreased muscle strength, fatigue and metabolic disorders initiated by a reduction in skeletal muscle mass, which is characterized by atrophy and reduction of muscle tissue quality. In the sarcopenic processes, muscle fibers are replaced by fibrotic tissue, resulting in increased frailty and function deterioration, with neuromuscular junction degeneration and alterations in oxidative stress and muscle metabolism [3].

The pathogenesis of sarcopenia is complex and multifactorial. It may include disuse, altered endocrine function, chronic diseases, inflammation, insulin resistance, and nutritional deficiencies [4]. In conditions such as malignancy, rheumatoid arthritis, and aging, the loss of muscle mass may be associated with preserved or even increased 
body fat content. Consequently, there could be marked weakness despite normal weight; this condition is called "sarcopenic obesity" [5] (Fig. 1).

Obesity and sarcopenia may potentiate each other and act synergistically causing physical impairment and metabolic disorders, and worsening prognosis. Moreover, increasing visceral fat content may promote the secretion of proinflammatory cytokines, leading to a catabolic effect on muscles, as well as insulin resistance [6]. Several studies have recently reported that inflammation may be directly associated with sarcopenia [7].

Although sarcopenia may be a component of cachexia, the two conditions differ. "Cachexia" is a term originating from the Greek kakos and hexis, meaning "bad condition" and defining those patients who lose more than $5 \%$ of body weight within 12 months or less [8]. Among GC patients, about $85 \%$ develop cachexia [9]. The cachectic state is a lifethreatening syndrome observed in many pathological conditions other than cancer, such as chronic obstructive pulmonary disease, sepsis, and chronic heart failure [10, 11]. It encompasses skeletal muscle and adipose tissue loss, and it is frequently associated with muscle atrophy and a deregulated metabolic state with increased basal energy expenditure and resistance to conventional nutritional support [12]. In contrast, the nonmuscle protein compartment is relatively preserved, thus distinguishing cachexia from starvation [13]. Additionally, cachexia-associated cytokines are able to cross the blood-brain barrier and modify the activity of hunger regulatory systems. As a result, cancer patients with cachexia often develop anorexia, the incidence rate of which ranges from $15 \%$ to $40 \%$ [14].

Cachexia contributes substantially to morbidity and mortality in cancer patients, accounting for more than $20 \%$ of cancer deaths [12, 15] [15]. Chronic inflammation with elevated levels of circulating inflammatory cytokines is consistently observed in cachectic cancer patients. Tumor cells produce both proinflammatory and procachectic factors, which stimulate a host inflammatory response. Procachectic factors include proteolysis-inducing and lipidmobilizing factors $[12,16]$. Inflammatory cytokines may trigger muscle wasting by increasing the level of nuclear factor $\kappa B$ or by causing the release of other cytokines. Tumor necrosis factor $\alpha$ and proteolysis-inducing factor cause skeletal muscle atrophy in cachectic patients as they both increase protein degradation through the ubiquitinproteasome pathway and reduce protein synthesis through phosphorylation of eukaryotic initiation factor $2 \alpha$ [17]. Other factors overexpressed in cancer cachexia include angiotensin II, myostatin, and activin A, whose upregulation inhibits muscle growth [9].

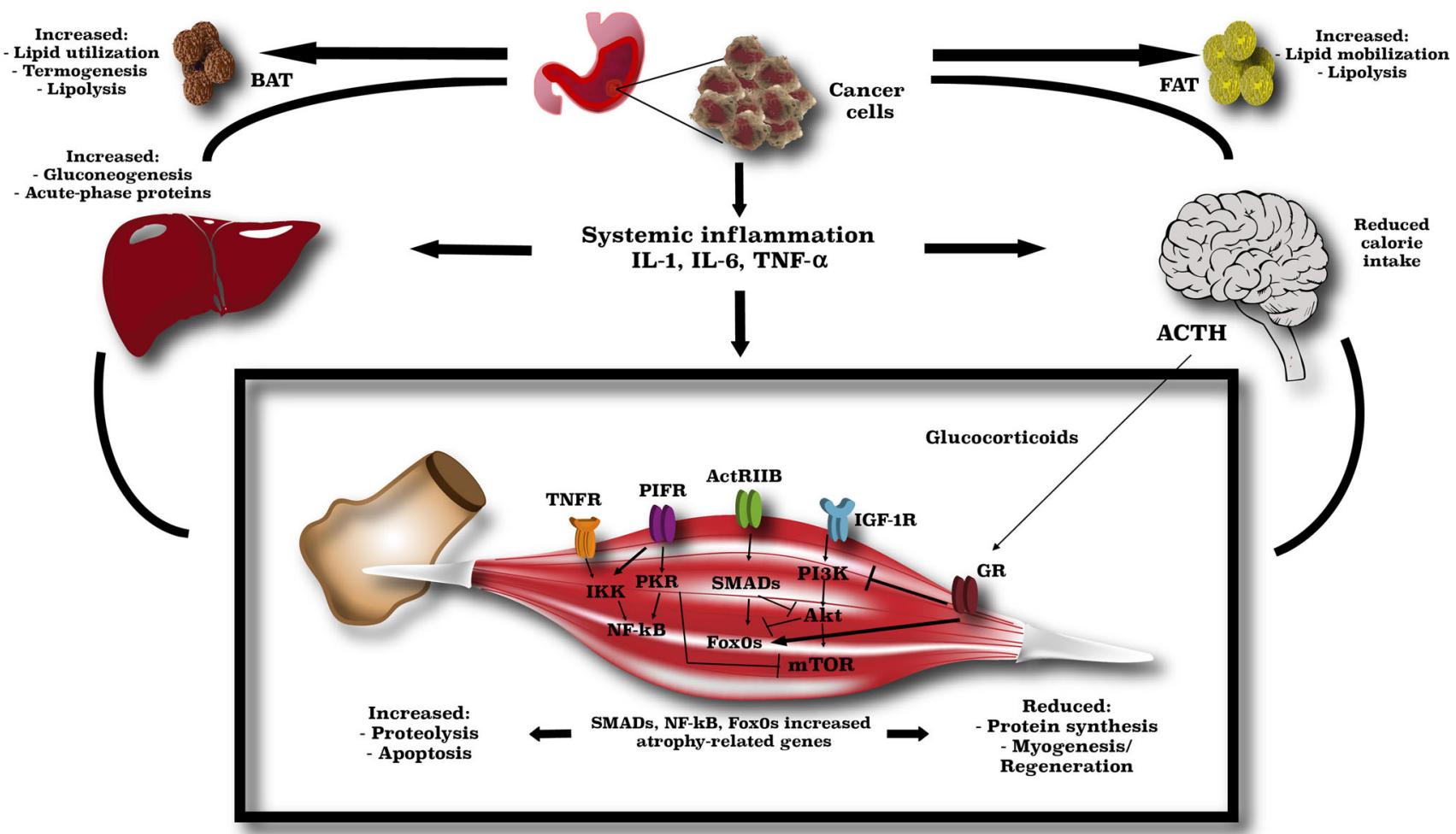

Fig. 1 Principal molecular pathways underpinning sarcopenia development. ACTH adrenocorticotropic hormone, ActRIIB , BAT brown adipose tissue, $G R$ glucocorticoid receptor, $I G F-1 R$ insulin-like growth factor 1 receptor, $I L$ interleukin, $I K K \mathrm{I} \kappa \mathrm{B}$ kinase, $m T O R$ mammalian target of rapamycin, $N F-\kappa B$ nuclear factor $\kappa \mathrm{B}, P I 3 K$ phosphatidylinositol 3-kinase, $P I F R, P K R, T N F$ tumor necrosis factor, TNFR tumor necrosis factor receptor 
Additionally, a number of neuroendocrine factors may also be deregulated, leading to insulin resistance, reduced anabolic activity, and elevated cortisol levels, and are potential targets for therapeutic interventions [16].

Here we review the role of sarcopenia onset in the management of GC to better understand its prognostic impact and potential improvements in all the settings of GC treatment.

\section{Impact of sarcopenia on the surgical management of GC}

Despite the development of new therapeutic options, gastric surgery with adequate lymph node dissection remains the mainstay of treatment for patients with resectable GC $[18,19]$. However, gastrectomy is associated with significant risks of postoperative complications, morbidity, and death [20]. Moreover, GC mainly affects elderly people, and the association between advanced age and less favorable postoperative outcomes has been widely demonstrated $[21,22]$. In addition, since the incidence of malnutrition in GC patients ranges from $60 \%$ to $85 \%[23,24]$ and represents a well-known prognostic factor and an important determinant of frailty, a preoperative nutritional assessment is a key step to overcome possible complications.

Sarcopenia is an independent predictor of postsurgical outcomes in many types of gastrointestinal cancers [25-27], including GC [19]. The American College of Surgeons highlighted the importance of incorporating both sarcopenia and frailty in the preoperative risk assessment of older GC patients [28]. Tegels et al. [29] described a strong correlation between these two factors and postoperative mortality after gastric surgery. Additionally, preoperative hypolbuminemia and poor nutritional status, low hemoglobin levels, and the presence of comorbidities such as diabetes were associated with sarcopenia, frailty, and consequently poor short-term and long-term outcomes [22, 30, 31]. The reasons why sarcopenia independently predicts major complications in GC patients undergoing gastrectomy has been hypothesized [2]. Firstly, the association between sarcopenia and indexes of poor nutritional status (low BMI, low albumin levels) could increase the postsurgical complication rate [32]. Secondly, the loss of muscle mass and function would decrease physical ability and autonomy in daily activities, hindering the normal postoperative recovery [33]. Thirdly, sarcopenia correlates with a higher postsurgical infection rate, longer hospitalization, more frequent need for mechanical ventilation, and a greater number of hospital readmissions and rehabilitation programs [34], with increased health care costs [35].

With respect to long-term postsurgical outcome, sarcopenia was independently associated with overall survival and disease-free survival. Compared with indolent tumors, cancers with more aggressive behavior tended to have higher metabolic activity, leading to systemic inflammation and sarcopenia [36]. Some authors have also suggested the potential role of myokines, reporting an increased rate of GC relapse due to the depletion of muscle mass and the consequent reduction of myokine secretion; these molecules seem to inhibit the growth of cancer cells [37]. Moreover, sarcopenia was associated with toxicity in GC patients undergoing neoadjuvant [38] or adjuvant [2] treatment, leading to early discontinuation of chemotherapy, reduced efficacy of anticancer drugs, and poor prognosis. Finally, the previously mentioned high postoperative complication rate contributes to worse long-term prognosis $[19,39]$.

The effect on overall survival and disease-free survival seems to be more evident in stage II and stage III GC patients; Zhuang et al. [2] found that sarcopenic patients had a significantly shorter overall survival (hazard ratio 1.653, $p<0.001$ ) and a significantly lower disease-free survival rate (hazard ratio $1.620, p<0.001)$ than nonsarcopenic patients when adjustment was made for disease stage. This is probably due to the most likely development of sarcopenia in patients with more aggressive tumors.

Notably, different stages of sarcopenia as defined by the European Working Group on Sarcopenia [5] seem to impact differently on postoperative outcome. Huang et al. [40] highlighted the importance of sarcopenia classification in stratifying the risk of postoperative complications. They reported worse postgastrectomy outcomes with advancing sarcopenia stages; furthermore, the three-grade classification (presarcopenia, sarcopenia, and severe sarcopenia) seemed to independently predict postoperative complications. To distinguish the different grades of sarcopenia, it is crucial to evaluate not only skeletal muscle mass but also muscle function and physical ability.

Sarcopenic obesity is another emerging point to consider in the preoperative evaluation of GC patients. A sixfold increased risk of postoperative complications in obese sarcopenic patients undergoing gastrectomy has been reported [41, 42], as well as a higher risk of infection after laparoscopic gastrectomy.

Finally, the early integration of nutritional screening [23] and prehabilitation programs such as preoperative exercises to increase muscle mass combined with personalized nutritional support [40] was demonstrated to be crucial in reversing sarcopenia and improving short-term and long-term gastrectomy-related outcomes.

\section{Nutrition in GC patients: risk assessments and nutritional treatment}

Historically, malnutrition has been recognized as an important prognostic factor in cancer patients, with a shorter survival reported in patients who experienced 
weight loss before chemotherapy [43]. In GC patients, malnutrition may arise from the obstructive effect of the tumor [12] and may be increased by treatment-related side effects.

Beyond anthropometric measures, biochemical and functional indicators such as C-reactive protein and albumin blood concentration are helpful to identify malnutrition through grading scales for a risk assessment score [44]. In recent years, several tools for the evaluation of nutritional status have been developed, such as the Mini Nutritional Assessment (MNA) [45] and the Subjective Global Assessment (SGA) [46]. The first one was developed to provide a quick nutritional assessment of elderly patients through the evaluation of their height, weight, weight loss, lifestyle, dietary intake, mobility, and comorbidities. After its validation in clinical practice, it became a useful tool also in oncology. The SGA was compared with six other objective techniques (serum albumin level, transferrin level, anthropometry, ideal weight, body fat percentage, total lymphocyte count, and creatinine-height index) in surgical patients, and was found to be the most sensitive and specific tool to predict nutrition-related complications.

Later, Bauer et al. [47] investigated the potential role of the Patient-Generated SGA (PG-SGA), showing higher accuracy in identifying malnourished cancer patients than the SGA, with a sensitivity of $98 \%$ and a specificity of $82 \%$. The PG-SGA provides an overall global rating divided into three categories: well nourished, moderately malnourished or suspected of being malnourished, and severely malnourished. Notably, the Oncology Nutrition Dietetic Practice Group of the American Dietetic Association adopted this scale as the standard tool for nutrition assessment for cancer patients.

The nutritional risk index (NRI) is another useful tool to stratify nutritional risk [48] in GC patients undergoing surgery. The NRI is a simple equation that uses serum albumin concentration and recent weight loss to identify malnourished patients. A low NRI was associated with a higher risk of surgical wound complications. Similarly, the prognostic nutritional index is calculated with the serum albumin concentration and lymphocytes count in peripheral blood [49]. Another nutritional screening tool widely used also in GC surgical patients is the Nutritional Risk Screening 2002 [50, 51], which is endorsed by the European Society for Clinical Nutrition and Metabolism and evaluates nutritional risk, taking into account both the nutritional status and the severity of the disease.

Considering the limitations in the accurate measurement of nutritional status and different available tools, a combination of objective variables (anthropometric and laboratory measurements) and a subjective scoring system is necessary to optimally treat potentially resectable GC patients.
As the preoperative nutritional condition of patients undergoing surgery can directly influence postoperative prognosis, overall survival, and disease-free survival, a timely and appropriate preoperative nutritional support may improve postsurgical outcomes of GC patients [52].

Even though parenteral nutrition or preoperative enteral nutrition was associated with a better prognosis and fewer postoperative complications [53], the addition of immunestimulating nutrients did not correlate with lower mortality rates in surgically resected GC patients (risk ratio 1.1, 95\% confidence interval 0.93-1.31) according to a systematic review of 2419 patients from 22 randomized clinical trials [54].

Similarly, postoperative nutritional support plays a crucial role in the management of the catabolic effect of gastrointestinal surgery. Early enteral feeding soon followed by solid soft food on the third postoperative day is feasible, safe, and associated with shorter hospitalization [55-57].

Moreover, since up to $50 \%$ of resected GC patients develop anemia [58-60], because of multifactorial iron, folate, or vitamin $\mathrm{B}_{12}$ deficiency, evaluation of hemoglobin level should be planned, and appropriate replacement should be evaluated [61].

\section{Consequences of loss of skeletal muscle mass on chemotherapy tolerance}

Loss of muscle mass is a key factor in determining tolerance of chemotherapy, as sarcopenia is associated with increased adverse events [4]. Unfortunately, muscle mass loss due to treatment-related adverse events or cancer itself may easily overlap and, the mechanisms by which this occurs are still unclear.

A first hypothesis to explain the decreased treatment tolerance is linked to pharmacokinetic distribution of chemotherapy drugs [4]. Notably, drug doses are usually administered by calculated body surface area (BSA). However, patients with similar BSA and BMI may have a significantly different body composition. Indeed, this calculation method may be potentially misleading because it does not consider adipose tissue compartment and lean body mass, mainly represented by skeletal muscle mass and tissues. Furthermore, many anticancer agents undergo hepatic and renal metabolism, and BSA is an imperfect indicator of changes concerning the function of the organs involved [62].

Since cytotoxic compounds have a narrow therapeutic index, understanding drug distribution is crucial. Patients with metabolic disorders usually experience variations in the distribution, metabolism, and clearance of chemotherapy agents. 
Obesity may mask a loss of muscle mass, with later elimination of highly lipophilic drugs in patients with increased adipose tissue [63]. In these patients, the administration of chemotherapy doses calculated according to the BSA can lead to overdosing of antineoplastic drugs per unit of body weight and to potentially serious side effects [64]. In addition, not only obese cancer patients with low muscle mass were reported to have shorter overall survival compared with patients with healthy muscle mass but also treatment-induced adverse events were increased [64].

Many antineoplastic agents are involved in the development of adverse events in sarcopenic patients [65-68]. Particularly, it has been demonstrated that 5 -fluorouracil increases the risk of loss of skeletal muscle mass and that patients treated with 5-fluorouracil who experienced significant adverse events had received higher doses of the drug when the number of kilograms of lean body mass was considered [65], suggesting the need for a dose adjustment according to weight and the lean body mass [69].

Similarly, in the evaluation of the potential role of S-1 in the adjuvant setting in GC, it has been demonstrated that patients with significant loss of muscle had poorer prognosis [70, 71]. Moreover, administration of S-1 for more than 6 months was identified as an independent risk factor for reduced muscle mass. Further, drugs that inhibit the phosphatidylinositol 3-kinase, AKT, and mammalian target of rapamycin pathway might lead to blockade of cellular hypertrophy and subsequently loss of muscle mass [68].

Likewise, esophagogastric cancer patients undergoing neoadjuvant chemotherapy had a shorter overall survival than patients with healthy muscle mass (569 days vs 1013 days respectively; $p=0.04$ ) [38]. Furthermore, patients with sarcopenia and chemotherapy-associated adverse events more often experienced dose reductions of 5 -fluorouracil than patients without muscle mass loss.

In a trial evaluating malnutrition in gastrointestinal cancer, patients were classified according the SGA scale as well-nourished patients (SGA-A) and malnourished patients (SGA-B and SGA-C), and it was demonstrated that the latter had more dose reductions compared with wellnourished patients. In particular, the proportion of patients who received chemotherapy in the first 8 weeks of treatment was $(88 \pm 17) \%$ among well-nourished upper gastrointestinal tract cancer patients and $(74 \pm 25) \%$ among moderately and severely malnourished upper gastrointestinal tract cancer patients $(p=0.01)$. Furthermore, a greater proportion of moderately and severely malnourished patients than well-nourished patients discontinued treatment because of adverse events (18\% vs 9\%, $p=0.08$ ), demonstrating a potential impact of sarcopenia on drug dose density [72].
As pharmacokinetics variability alone does not fully explain the possible relationship between sarcopenia and increased frequency of chemotherapy-related adverse events, other reasons for this association can be comorbidities and reduced functional status, which often characterize sarcopenic patients [4]. In addition, the link between sarcopenia and systemic inflammation may increase chemotherapy toxicity [44]. Inflammation reduces cytochrome activities, and impacts on drug metabolism and elimination, prolonging the exposure to cytotoxic treatments.

To date, the evidence is insufficient to change clinical practice, and it is still uncertain how to appropriate modify drug doses to prevent chemotherapy-related adverse events in sarcopenic patients.

Hence, further clinical trials should be conducted to evaluate dose reduction according to the calculation of muscle mass and muscle density, in order to prevent adverse events and to ensure greater treatment compliance.

\section{Nutritional support in patients with advanced GC}

Even when one is facing patients with inoperable or metastatic diseases, the early evaluation of their nutritional status and nutritional support is key to avoid sarcopenia onset and prevent or delay complications. Malnutrition occurs in up to $80 \%$ of advanced GC patients [44], insufficient nutrient absorption may cause severe weight loss [73], and the poor absorption of essential nutrients may further increase the risk of complications.

Similarly to early stages, in advanced GC patients the goal of nutritional therapy is to improve the nutritional status, to increase patients' adherence to systemic therapies, and to improve their quality of life. Nutritional support can be provided by oral, enteral, and/or parenteral nutrition [52]. Intuitively, enteral nutrition is more physiological than parenteral nutrition, preserving the structural and functional integrity of the gastrointestinal tract, is safer, is less expensive, and is a valid option for patients without dysphagia or obstruction [74].

Whenever a mechanical obstruction occurs, the placement of a stent may allow oral physiological nutrition and improve patients' quality of life. However, parenteral nutrition is mandatory in patients with impaired gastrointestinal function when inadequate food intake (less than $60 \%$ of the estimated energy intake) for more than 10 days can be expected, as also recommended by the European Society for Clinical Nutrition and Metabolism guidelines [75].

Whereas nourishment by central and peripheral veins ensures optimal nutrition, it increases the risk of infections when compared with enteral nutrition [76]; catheter-related 
bloodstream infections are the commonest and most serious complications in adult patients receiving parenteral nutrition [77], although strict adherence to meticulous insertion and management policies may effectively reduce catheter-related complications [78]. In terminal-stage disease the benefit of nutritional support is limited, and may be associated with an increased risk of complications; in these cases, nutritional support is recommended only when benefits prevail over any possible risk [75].

Moreover, home parenteral nutrition is recommended for weight stabilization and therapy continuation for patients experiencing chemotherapy-related gastrointestinal adverse events [75, 79]. In addition, home parenteral nutrition is associated with an improvement in quality of life, performance status, and nutritional status in advanced cancer patients with compromised enteral intake and malnutrition, regardless of their tumor type [80]. Thus, total home parenteral nutrition is mandatory for malnourished patients with peritoneal carcinomatosis and severe impairment of gastrointestinal function [81], as well as in the case of short bowel syndrome due to extensive surgery [82].

Studies show that the main factors influencing the success of parenteral nutrition are patient adherence, adequate support by a professional and committed nutritionist, and effective cooperation between the patient, nutritionist, treating physicians, and home care provider [83].

\section{Target therapies and future perspectives}

As sarcopenia and cachexia have an important impact on GC cancer patients' prognosis, many novel molecules, including anabolic agents and anti-inflammatory drugs, have been developed [84]. An extensive amount of data support the administration of megestrol acetate and medroxyprogesterone acetate, with various indications in cancer patients, including appetite stimulation, weight gain, and downregulation of proinflammatory cytokines $[85,86]$.

To confirm the role in preventing and treating anorex$\mathrm{ia} /$ cachexia syndrome, the addition of thalidomide to megestrol acetate therapy was investigated. A significant increase in body weight $(p<0.01)$, quality of life $(p=0.02), \quad$ appetite $(p=0.01), \quad$ and grip strength $(p=0.01)$ and a significant decrease in fatigue and Eastern Cooperative Oncology Group performance status $(p=0.03)$ were found in the experimental arm, showing a higher effectiveness for combination treatment [87]. Further combinations of megestrol acetate and other compounds, such as formeterol acetate or mirtazapine, are being evaluated [88, 89]. Similarly, corticosteroids could improve appetite, energy, and well-being.
As melatonin was found to be involved in appetite and nutrient absorption [90], its potential role for appetite improvement in cachectic cancer patients was investigated in a double-blind randomized trial. Patients received $20 \mathrm{mg}$ melatonin per night or matching placebo for 28 days. The trial was closed early because of futility as no differences in appetite were reported between the treatment arms in an interim analysis [91].

After initial enthusiasm [92, 93], enobosarm-a muscular and bone testosterone receptor agonist-failed to result in an improvement in physical function in advanced non-small-cell lung cancer patients despite an increase in lean body mass [94-98].

In addition, anamorelin hydrochloride, an orally active ghrelin receptor agonist, was tested in two parallel phase III trials. In both studies, ROMANA 1 [99] and ROMANA 2 [100], $100 \mathrm{mg}$ anamorelin hydrochloride or matching placebo was given daily at least $1 \mathrm{~h}$ before a meal in addition to platinum and taxanes or platinum and nontaxane-based chemotherapy for non-small-cell lung cancer patients. In both trials, patients exposed to anamorelin hydrochloride had a significantly increased lean body mass $(p<0.0001)$ when compared to those treated with placebo; moreover, anamorelin hydrochloride was associated with increased body weight $(p<0.0001)$, and improved patient symptoms $(p=0.0004$ and $p=0.0016)$.

However, both trials failed to show an increase in handgrip strength, the secondary end point of the two studies. Thus, considering the so far unmet need of active drugs for the treatment of cancer-related anorexia/cachexia syndrome, anamorelin hydrochloride could be considered as an available option [101]. Complete results of further trials investigating the effect of this compound on primary clinical outcomes (e.g., overall survival, disease-free survival, treatment tolerance) are still awaited [102] (Table 1).

Thus, considering the complex pathogenesis of sarcopenia, cachexia, and cancer development, clinical treatment of GC patients should include a multimodal approach. Despite various efforts so far, this multifactorial syndrome still impacts on patient outcome. Hence, extended results of ongoing trials, the development of new drugs, and increased awareness of nutritional support issues among oncologists are eagerly awaited to better tailor GC patients treatments [103].

\section{Conclusions}

Sarcopenia is a multifactorial clinical condition that leads to prolonged hospitalization, a higher degree of treatmentrelated toxicity and postsurgical complications, reduced response to cancer treatment, impaired quality of life, and a worse prognosis in GC patients. 
Table 1 Principal compounds tested

\begin{tabular}{|c|c|c|c|c|c|c|}
\hline Trial & Phase & Population & Treatment & $n$ & Primary end point & Results \\
\hline $\begin{array}{l}\text { Del Fabbro et al. } \\
\text { [91] }\end{array}$ & III & $\begin{array}{l}\text { Advanced GC or } \\
\text { NSCLC patients }\end{array}$ & Melatonin vs placebo & 73 (R 1:1) & Appetite & $p=0.78, \mathrm{NS}$ \\
\hline \multirow[t]{3}{*}{ López et al. [86] } & \multirow{3}{*}{$\begin{array}{l}\text { Cochrane } \\
\text { meta- } \\
\text { analysis }\end{array}$} & \multirow[t]{3}{*}{ Unselected patients } & \multirow[t]{3}{*}{ MA vs placebo } & \multirow[t]{3}{*}{3368} & Appetite & $\begin{array}{c}\text { RR } 2.31(95 \% \text { CI } \\
1.52-3.59)\end{array}$ \\
\hline & & & & & Weight gain & $\begin{array}{c}\text { RR } 1.88(95 \% \text { CI } \\
1.43-2.47)\end{array}$ \\
\hline & & & & & HRQoL & $\begin{array}{c}\text { RR } 1.52(95 \% \text { CI } \\
1.00-2.30)\end{array}$ \\
\hline \multirow[t]{3}{*}{ Wen et al. [87] } & \multirow[t]{3}{*}{ II } & \multirow{3}{*}{$\begin{array}{l}\text { Advanced cancer } \\
\text { patients }\end{array}$} & \multirow{3}{*}{$\begin{array}{l}\text { MA plus thalidomide } \\
\text { vs MA }\end{array}$} & \multirow[t]{3}{*}{$102(\mathrm{R} 1: 1)$} & Body weight & $p=0.05$ \\
\hline & & & & & Fatigue & $p<0.01$ \\
\hline & & & & & QoL & $p<0.01$ \\
\hline \multirow[t]{2}{*}{ Greig et al. [88] } & \multirow[t]{2}{*}{$\mathrm{I} / \mathrm{II}$} & \multirow[t]{2}{*}{$\begin{array}{l}\text { Advanced cancer } \\
\text { patients }\end{array}$} & \multirow[t]{2}{*}{$\begin{array}{l}\text { MA plus formoterol } \\
\text { fumarate }\end{array}$} & \multirow[t]{2}{*}{14} & $\begin{array}{l}\text { Mean quadriceps } \\
\text { volume, }\end{array}$ & $p=0.012$ \\
\hline & & & & & Hand-grip strength & $p>0.05$ \\
\hline $\begin{array}{c}\text { POWER trials } \\
{[94,97,98]}\end{array}$ & II & $\begin{array}{l}\text { Advanced NSCLC } \\
\text { patients }\end{array}$ & $\begin{array}{l}\text { Enobosarm vs } \\
\text { placebo }\end{array}$ & $600(\mathrm{R} 1: 1)$ & Lean body mass & Ongoing \\
\hline ROMANA I [99] & III & $\begin{array}{l}\text { Advanced NSCLC } \\
\text { patients }\end{array}$ & $\begin{array}{l}\text { Anamorelin vs } \\
\text { placebo }\end{array}$ & 484 (R 2:1) & Lean body mass & $p<0.0001$ \\
\hline ROMANA II [100] & III & $\begin{array}{l}\text { Advanced NSCLC } \\
\text { patients }\end{array}$ & $\begin{array}{l}\text { Anamorelin vs } \\
\text { placebo }\end{array}$ & 495 (R 2:1) & Lean body mass & $p<0.0001$ \\
\hline
\end{tabular}

$C I$ confidence interval, $G C$ gastric cancer, $H R Q o L$ health-related quality of life, $M A$ megestrol acetate, $N S$ not significant, $N S C L C$ non-small-cell lung cancer, $Q o L$ quality of life $R$ randomization, $R R$ risk ratio

Early evaluations of nutritional status, including body composition assessment, and timely nutritional support are key aspects in the treatment of GC patients with both operable and advanced disease. A multimodal approach is necessary to improve clinical outcomes and guarantee an appropriate support therapy for cancer patients. It should involve the structured collaboration between oncologists, surgeons, physiatrists, and clinical nutritionists.

New drugs to counteract lean body mass loss and enhance the efficacy of nutritional support in cancer patients are urgently needed. At the same time, clinical trials should be conducted to calculate the appropriate chemotherapy dosage according to muscle mass so as to prevent toxicity and adverse events and to ensure greater treatment adherence and efficacy.

\section{Compliance with ethical standards}

Conflict of interest The authors declare that they have no conflict of interest.

Ethical standards All the trials reported were conducted in accordance with the ethical standards of the responsible committee on human experimentation (institutional and national) and with the Helsinki Declaration of 1964 and later versions. According to the original publications, informed consent or substitute for it was obtained from all patients for their being included in each reported trial.

\section{References}

1. Torre LA, Bray F, Siegel RL, Ferlay J, Lortet-Tieulent J, Jemal A. Global cancer statistics, 2012. CA Cancer J Clin. 2015;65:87-108.

2. Zhuang C-L, Huang D-D, Pang W-Y, Zhou C-J, Wang S-L, Lou $\mathrm{N}$, et al. Sarcopenia is an independent predictor of severe postoperative complications and long-term survival after radical gastrectomy for gastric cancer: analysis from a large-scale cohort. Medicine (Baltimore). 2016;95:e3164.

3. Ryall JG, Schertzer JD, Lynch GS. Cellular and molecular mechanisms underlying age-related skeletal muscle wasting and weakness. Biogerontology. 2008;9:213-28.

4. Antoun S, Borget I, Lanoy E. Impact of sarcopenia on the prognosis and treatment toxicities in patients diagnosed with cancer. Curr Opin Support Palliat Care. 2013;7:383-9.

5. Cruz-Jentoft AJ, Baeyens JP, Bauer JM, Boirie Y, Cederholm T, Landi F, et al. Sarcopenia: European consensus on definition and diagnosis: report of the European Working Group on Sarcopenia in Older People. Age Ageing. 2010;39:412-23.

6. Buch A, Carmeli E, Boker LK, Marcus Y, Shefer G, Kis O, et al. Muscle function and fat content in relation to sarcopenia, obesity and frailty of old age-an overview. Exp Gerontol. 2016;76:25-32.

7. Santilli V, Bernetti A, Mangone M, Paoloni M. Clinical definition of sarcopenia. Clin Cases Miner Bone Metab. 2014;11:177-80.

8. Yoshida T, Delafontaine P. Mechanisms of cachexia in chronic disease states. Am J Med Sci. 2015;350:250-6.

9. Fielitz J. Cancer cachexia-when proteasomal inhibition is not enough. J Cachexia Sarcopenia Muscle. 2016;7:239-45. 
10. Argilés JM, López-Soriano FJ, Toledo M, Betancourt A, Serpe $\mathrm{R}$, Busquets S. The cachexia score (CASCO): a new tool for staging cachectic cancer patients. J Cachexia Sarcopenia Muscle. 2011;2:87-93.

11. Argilés JM, Fontes-Oliveira CC, Toledo M, López-Soriano FJ, Busquets S. Cachexia: a problem of energetic inefficiency. J Cachexia Sarcopenia Muscle. 2014;5:279-86.

12. Donohoe CL, Ryan AM, Reynolds JV. Cancer cachexia: mechanisms and clinical implications. Gastroenterol Res Pract. 2011;2011:601434.

13. Tisdale MJ. Mechanisms of cancer cachexia. Physiol Rev. 2009;89:381-410.

14. Ezeoke CC, Morley JE. Pathophysiology of anorexia in the cancer cachexia syndrome. J Cachexia Sarcopenia Muscle. 2015;6:287-302.

15. Fearon K, Strasser F, Anker SD, Bosaeus I, Bruera E, Fainsinger RL, et al. Definition and classification of cancer cachexia: an international consensus. Lancet Oncol. 2011;12:489-95.

16. Skipworth RJE, Stewart GD, Dejong CHC, Preston T, Fearon $\mathrm{KCH}$. Pathophysiology of cancer cachexia: much more than host-tumour interaction? Clin Nutr. 2007;26:667-76.

17. Tisdale MJ. Cancer cachexia. Curr Opin Gastroenterol. 2010;26:146-51.

18. Thrumurthy SG, Chaudry MA, Hochhauser D, Mughal M. The diagnosis and management of gastric cancer. BMJ. 2013;347:f6367.

19. Wang S-L, Zhuang C-L, Huang D-D, Pang W-Y, Lou N, Chen F-F, et al. Sarcopenia adversely impacts postoperative clinical outcomes following gastrectomy in patients with gastric cancer: a prospective study. Ann Surg Oncol. 2016;23:556-64.

20. Papenfuss WA, Kukar M, Oxenberg J, Attwood K, Nurkin S, Malhotra U, et al. Morbidity and mortality associated with gastrectomy for gastric cancer. Ann Surg Oncol. 2014;21:3008-14.

21. Takeshita H, Ichikawa D, Komatsu S, Kubota T, Okamoto K, Shiozaki A, et al. Surgical outcomes of gastrectomy for elderly patients with gastric cancer. World J Surg. 2013;37:2891-8.

22. Wagner D, DeMarco MM, Amini N, Buttner S, Segev D, Gani $\mathrm{F}$, et al. Role of frailty and sarcopenia in predicting outcomes among patients undergoing gastrointestinal surgery. World $\mathrm{J}$ Gastrointest Surg. 2016;8:27-40.

23. Gavazzi C, Colatruglio S, Sironi A, Mazzaferro V, Miceli R. Importance of early nutritional screening in patients with gastric cancer. Br J Nutr. 2011;106:1773-8.

24. Hébuterne X, Lemarié E, Michallet M, de Montreuil CB, Schneider SM, Goldwasser F. Prevalence of malnutrition and current use of nutrition support in patients with cancer. JPEN J Parenter Enteral Nutr. 2014;38:196-204.

25. Mei KL, Batsis JA, Mills JB, Holubar SD. Sarcopenia and sarcopenic obesity: do they predict inferior oncologic outcomes after gastrointestinal cancer surgery? Perioper. Med (Lond). 2016;5:30.

26. Lieffers JR, Bathe OF, Fassbender K, Winget M, Baracos VE. Sarcopenia is associated with postoperative infection and delayed recovery from colorectal cancer resection surgery. Br J Cancer. 2012;107:931-6.

27. Voron T, Tselikas L, Pietrasz D, Pigneur F, Laurent A, Compagnon $\mathrm{P}$, et al. Sarcopenia impacts on short- and long-term results of hepatectomy for hepatocellular carcinoma. Ann Surg. 2015;261:1173-83.

28. Chow WB, Rosenthal RA, Merkow RP, Ko CY, Esnaola NF. Optimal preoperative assessment of the geriatric surgical patient: a best practices guideline from the American College of Surgeons National Surgical Quality Improvement Program and the American Geriatrics Society. J Am Coll Surg. 2012;215:453-66.
29. Tegels JJW, De Maat MFG, Hulsewé KWE, Hoofwijk AGM, Stoot JHMB. Improving the outcomes in gastric cancer surgery. World J Gastroenterol. 2014;20:13692-704.

30. Amrock LG, Neuman MD, Lin H-M, Deiner S. Can routine preoperative data predict adverse outcomes in the elderly? Development and validation of a simple risk model incorporating a chart-derived frailty score. J Am Coll Surg. 2014;219:684-94.

31. Yamashita K, Ushiku H, Katada N, Hosoda K, Moriya H, Mieno $\mathrm{H}$, et al. Reduced preoperative serum albumin and absence of peritoneal dissemination may be predictive factors for long-term survival with advanced gastric cancer with positive cytology test. Eur J Surg Oncol. 2015;41:1324-32.

32. Hall JC. Nutritional assessment of surgery patients. J Am Coll Surg. 2006;202:837-43.

33. Hayashi T, Yoshikawa T, Aoyama T, Ogata T, Cho H, Tsuburaya A. Severity of complications after gastrectomy in elderly patients with gastric cancer. World J Surg. 2012;36:2139-45.

34. Peterson SJ, Braunschweig CA. Prevalence of sarcopenia and associated outcomes in the clinical setting. Nutr Clin Pract. 2016;31:40-8.

35. Janssen I, Shepard DS, Katzmarzyk PT, Roubenoff R. The healthcare costs of sarcopenia in the United States. J Am Geriatr Soc. 2004;52:80-5.

36. Dodson S, Baracos VE, Jatoi A, Evans WJ, Cella D, Dalton JT, et al. Muscle wasting in cancer cachexia: clinical implications, diagnosis, and emerging treatment strategies. Annu Rev Med. 2011;62:265-79.

37. Pedersen BK, Febbraio MA. Muscles, exercise and obesity: skeletal muscle as a secretory organ. Nat Rev Endocrinol. 2012;8:457-65.

38. Tan BHL, Brammer K, Randhawa N, Welch NT, Parsons SL, James EJ, et al. Sarcopenia is associated with toxicity in patients undergoing neo-adjuvant chemotherapy for oesophago-gastric cancer. Eur J Surg Oncol. 2015;41:333-8.

39. Fukuda Y, Yamamoto K, Hirao M, Nishikawa K, Nagatsuma Y, Nakayama T, et al. Sarcopenia is associated with severe postoperative complications in elderly gastric cancer patients undergoing gastrectomy. Gastric Cancer. 2016;19:986-93.

40. Huang D-D, Zhou C-J, Wang S-L, Mao S-T, Zhou X-Y, Lou N, et al. Impact of different sarcopenia stages on the postoperative outcomes after radical gastrectomy for gastric cancer. Surgery. 2017;161:680-93.

41. Nishigori T, Tsunoda S, Okabe H, Tanaka E, Hisamori $\mathrm{S}$, Hosogi $\mathrm{H}$, et al. Impact of sarcopenic obesity on surgical site infection after laparoscopic total gastrectomy. Ann Surg Oncol. 2016;23:524-31.

42. Lou N, Chi C-H, Chen X-D, Zhou C-J, Wang S-L, Zhuang C-L, et al. Sarcopenia in overweight and obese patients is a predictive factor for postoperative complication in gastric cancer: a prospective study. Eur J Surg Oncol. 2017;43:188-95.

43. Dewys WD, Begg C, Lavin PT, Band PR, Bennett JM, Bertino JR, et al. Prognostic effect of weight loss prior to chemotherapy in cancer patients. Am J Med. 1980;69:491-7.

44. Deans DAC, Tan BH, Wigmore SJ, Ross JA, de Beaux AC, Paterson-Brown S, et al. The influence of systemic inflammation, dietary intake and stage of disease on rate of weight loss in patients with gastro-oesophageal cancer. Br J Cancer. 2009;100:63-9.

45. Vellas B, Guigoz Y, Garry PJ, Nourhashemi F, Bennahum D, Lauque $\mathrm{S}$, et al. The mini nutritional assessment (MNA) and its use in grading the nutritional state of elderly patients. Nutrition. 1999;15:116-22.

46. Detsky AS, Baker JP, O'Rourke K, Johnston N, Whitwell J, Mendelson RA, et al. Predicting nutrition-associated complications for patients undergoing gastrointestinal surgery. J Parenter Enteral Nutr. 1987;11:440-6. 
47. Bauer J, Capra S, Ferguson M. Use of the scored patient-generated subjective global assessment (PG-SGA) as a nutrition assessment tool in patients with cancer. Eur $\mathrm{J}$ Clin Nutr. 2002;56:779-85.

48. Veterans Affairs Total Parenteral Nutrition Cooperative Study Group. Perioperative total parenteral nutrition in surgical patients. N Engl J Med. 1991;325:525-32.

49. Nozoe T, Ninomiya M, Maeda T, Matsukuma A, Nakashima H, Ezaki T. Prognostic nutritional index: a tool to predict the biological aggressiveness of gastric carcinoma. Surg Today. 2010;40:440-3.

50. Qiu M, Zhou Y, Jin Y, Wang Z, Wei X, Han H, et al. Nutrition support can bring survival benefit to high nutrition risk gastric cancer patients who received chemotherapy. Support Care Cancer. 2015;23:1933-9.

51. Kondrup J, Rasmussen HH, Hamberg O, Stanga Z, An Ad Hoc ESPEN Working Group. Nutritional risk screening (NRS 2002): a new method based on an analysis of controlled clinical trials. Clin. Nutr. 2003;22:321-36.

52. Caccialanza R, Pedrazzoli P, Cereda E, Gavazzi C, Pinto C, Paccagnella A, et al. Nutritional support in cancer patients: a position paper from the Italian Society of Medical Oncology (AIOM) and the Italian Society of Artificial Nutrition and Metabolism (SINPE). J. Cancer. 2016;7:131-5.

53. Sungurtekin H, Sungurtekin U, Balci C, Zencir M, Erdem E. The influence of nutritional status on complications after major intraabdominal surgery. J Am Coll Nutr. 2004;23:227-32.

54. Heyland DK, Novak F, Drover JW, Jain M, Su X, Suchner U. Should immunonutrition become routine in critically ill patients? A systematic review of the evidence. JAMA. 2001;286:944-53.

55. Gabor S, Renner H, Matzi V, Ratzenhofer B, Lindenmann J, Sankin O, et al. Early enteral feeding compared with parenteral nutrition after oesophageal or oesophagogastric resection and reconstruction. Br J Nutr. 2005;93:509-13.

56. Hur H, Si Y, Kang WK, Kim W, Jeon HM. Effects of early oral feeding on surgical outcomes and recovery after curative surgery for gastric cancer: pilot study results. World J Surg. 2009;33:1454-8.

57. Kreymann KG. Early nutrition support in critical care: a European perspective. Curr Opin Clin Nutr Metab Care. 2008;11:156-9.

58. Skroubis G, Sakellaropoulos G, Pouggouras K, Mead N, Nikiforidis G, Kalfarentzos F. Comparison of nutritional deficiencies after Roux-en-Y gastric bypass and after biliopancreatic diversion with Roux-en-Y gastric bypass. Obes Surg. 2002;12:551-8.

59. Lim C-H, Kim SW, Kim WC, Kim JS, Cho YK, Park JM, et al. Anemia after gastrectomy for early gastric cancer: long-term follow-up observational study. World J Gastroenterol. 2012;18:6114-9.

60. Beyan C, Beyan E, Kaptan K, Ifran A, Uzar AI. Post-gastrectomy anemia: evaluation of 72 cases with post-gastrectomy anemia. Hematology 2007;12:81-4.

61. Jun J-H, Yoo JE, Lee JA, Kim YS, Sunwoo S, Kim BS, et al. Anemia after gastrectomy in long-term survivors of gastric cancer: a retrospective cohort study. Int J Surg. 2016;28:162-8.

62. Gurney H. Dose calculation of anticancer drugs: a review of the current practice and introduction of an alternative. J Clin Oncol. 1996;14:2590-611.

63. Ryan AM, Power DG, Daly L, Cushen SJ, Ní Bhuachalla Ē, Prado CM. Cancer-associated malnutrition, cachexia and sarcopenia: the skeleton in the hospital closet 40 years later. Proc Nutr Soc. 2016;75:199-211.

64. Prado CMM, Lieffers JR, McCargar LJ, Reiman T, Sawyer MB, Martin L, et al. Prevalence and clinical implications of sarcopenic obesity in patients with solid tumours of the respiratory and gastrointestinal tracts: a population-based study. Lancet Oncol. 2008;9:629-35.

65. Prado CMM, Baracos VE, McCargar LJ, Mourtzakis M, Mulder $\mathrm{KE}$, Reiman $\mathrm{T}$, et al. Body composition as an independent determinant of 5-fluorouracil-based chemotherapy toxicity. Clin Cancer Res. 2007;13:3264-8.

66. Cushen SJ, Power DG, Teo MY, MacEneaney P, Maher MM, McDermott R, et al. Body composition by computed tomography as a predictor of toxicity in patients with renal cell carcinoma treated with sunitinib. Am J Clin Oncol. 2017;40:47-52.

67. Mir O, Coriat R, Blanchet B, Durand J-P, Boudou-Rouquette P, Michels J, et al. Sarcopenia predicts early dose-limiting toxicities and pharmacokinetics of sorafenib in patients with hepatocellular carcinoma. PLoS One. 2012;7:e37563.

68. Gyawali B, Shimokata T, Honda K, Kondoh C, Hayashi N, Yoshino $\mathrm{Y}$, et al. Muscle wasting associated with the long-term use of mTOR inhibitors. Mol Clin Oncol. 2016;5:641-6.

69. Morgan DJ, Bray KM. Lean body mass as a predictor of drug dosage. Implications for drug therapy. Clin Pharmacokinet. 1994;26:292-307.

70. Andreyev HJ, Norman AR, Oates J, Cunningham D. Why do patients with weight loss have a worse outcome when undergoing chemotherapy for gastrointestinal malignancies? Eur. J. Cancer. 1990;1998(34):503-9.

71. Yamaoka Y, Fujitani K, Tsujinaka T, Yamamoto K, Hirao M, Sekimoto M. Skeletal muscle loss after total gastrectomy, exacerbated by adjuvant chemotherapy. Gastric Cancer. 2015;18:382-9.

72. Klute KA, Brouwer J, Jhawer M, Sachs H, Gangadin A, Ocean A, et al. Chemotherapy dose intensity predicted by baseline nutrition assessment in gastrointestinal malignancies: a multicentre analysis. Eur. J. Cancer. 1990;2016(63):189-200.

73. Ravasco P, Monteiro-Grillo I, Vidal PM, Camilo ME. Cancer: disease and nutrition are key determinants of patients' quality of life. Support Care Cancer. 2004;12:246-52.

74. Weimann A, Braga M, Harsanyi L, Laviano A, Ljungqvist O, Soeters $\mathrm{P}$, et al. ESPEN guidelines on enteral nutrition: surgery including organ transplantation. Clin Nutr. 2006;25:224-44.

75. Arends J, Bachmann P, Baracos V, Barthelemy N, Bertz H, Bozzetti $\mathrm{F}$, et al. ESPEN guidelines on nutrition in cancer patients. Clin Nutr. 2017;36:11-48.

76. Bozzetti F, Arends J, Lundholm K, Micklewright A, Zurcher G, Muscaritoli M, et al. ESPEN guidelines on parenteral nutrition: non-surgical oncology. Clin Nutr. 2009;28:445-54.

77. Dreesen M, Foulon V, Spriet I, Goossens GA, Hiele M, De Pourcq L, et al. Epidemiology of catheter-related infections in adult patients receiving home parenteral nutrition: a systematic review. Clin Nutr. 2013;32:16-26.

78. Cotogni P, Pittiruti M, Barbero C, Monge T, Palmo A, Boggio Bertinet D. Catheter-related complications in cancer patients on home parenteral nutrition: a prospective study of over 51,000 catheter days. J Parenter Enteral Nutr. 2013;37:375-83.

79. Rosania R, Chiapponi C, Malfertheiner P, Venerito M. Nutrition in patients with gastric cancer: an update. Gastrointest Tumors. 2016;2:178-87.

80. Vashi PG, Dahlk S, Popiel B, Lammersfeld CA, Ireton-Jones C, Gupta D. A longitudinal study investigating quality of life and nutritional outcomes in advanced cancer patients receiving home parenteral nutrition. BMC Cancer. 2014;14:593.

81. Shahmoradi N, Kandiah M, Peng LS. Impact of nutritional status on the quality of life of advanced cancer patients in hospice home care. Asian Pac J Cancer Prev. 2009;10:1003-9.

82. Winkler MF, Smith CE. Clinical, social, and economic impacts of home parenteral nutrition dependence in short bowel syndrome. JPEN J Parenter Enteral Nutr. 2014;38:32S-7S. 
83. Richter E, Denecke A, Klapdor S, Klapdor R. Parenteral nutrition support for patients with pancreatic cancer-improvement of the nutritional status and the therapeutic outcome. Anticancer Res. 2012;32:2111-8.

84. Aoyagi T, Terracina KP, Raza A, Matsubara H, Takabe K. Cancer cachexia, mechanism and treatment. World J Gastrointest Oncol. 2015;7:17-29.

85. Mantovani G, Macciò A, Bianchi A, Curreli L, Ghiani M, Santona MC, et al. Megestrol acetate in neoplastic anorexia/cachexia: clinical evaluation and comparison with cytokine levels in patients with head and neck carcinoma treated with neoadjuvant chemotherapy. Int J Clin Lab Res. 1995;25:135-41.

86. López AP, Roqué i Figuls M, Cuchi GU, Berenstein EG, Pasies BA, Alegre MB, et al. Systematic review of megestrol acetate in the treatment of anorexia-cachexia syndrome. J Pain Symptom Manage. 2004;27:360-9.

87. Wen H-S, Li X, Cao Y-Z, Zhang C-C, Yang F, Shi Y-M, et al. Clinical studies on the treatment of cancer cachexia with megestrol acetate plus thalidomide. Chemotherapy. 2012;58: 461-7.

88. Greig CA, Johns N, Gray C, MacDonald A, Stephens NA, Skipworth RJE, et al. Phase I/II trial of formoterol fumarate combined with megestrol acetate in cachectic patients with advanced malignancy. Support Care Cancer. 2014;22:1269-75.

89. ClinicalTrials.gov. Megestrol acetate with or without mirtazapine in treating cancer patients with weight loss or loss of appetite - full text view - ClinicalTrials.gov. https://clinicaltrials.gov/ct2/ show/NCT01501396?term=NCT01501396\&rank=1 (2014). Accessed 25 Jan 2017.

90. Motilva V, Cabeza J, Alarcón de la Lastra C. New issues about melatonin and its effects on the digestive system. Curr Pharm Des. 2001;7:909-31.

91. Del Fabbro E, Dev R, Hui D, Palmer L, Bruera E. Effects of melatonin on appetite and other symptoms in patients with advanced cancer and cachexia: a double-blind placebo-controlled trial. J Clin Oncol. 2013;31:1271-6.

92. Dalton JT, Barnette KG, Bohl CE, Hancock ML, Rodriguez D, Dodson ST, et al. The selective androgen receptor modulator GTx-024 (enobosarm) improves lean body mass and physical function in healthy elderly men and postmenopausal women: results of a double-blind, placebo-controlled phase II trial. J Cachexia Sarcopenia Muscle. 2011;2:153-61.

93. Srinath R, Dobs A. Enobosarm (GTx-024, S-22): a potential treatment for cachexia. Future Oncol. 2014;10:187-94.
94. Crawford J, Prado CMM, Johnston MA, Gralla RJ, Taylor RP, Hancock ML, et al. Study design and rationale for the phase 3 clinical development program of enobosarm, a selective androgen receptor modulator, for the prevention and treatment of muscle wasting in cancer patients (POWER trials). Curr Oncol Rep. 2016;18:37.

95. Cachexia Lok C. The last illness. Nature. 2015;528:182-3.

96. Crawford J, Johnston MA, Taylor RP, Dalton JT, Steiner MS. Enobosarm and lean body mass in patients with non-small cell lung cancer. J Clin Oncol. 2014;32(15 Suppl):9618.

97. ClinicalTrials.gov. Effect of GTx-024 on muscle wasting in patients with non-small cell lung cancer (NSCLC) on first line platinum - full text view - ClinicalTrials.gov. https://clin icaltrials.gov/ct2/show/NCT01355497?term=

NCT01355497\&rank=1 (2015). Accessed 25 Jan 2017.

98. ClinicalTrials.gov. Phase III study of the effect of GTx-024 on muscle wasting in patients with non-small cell lung cancer (NSCLC) - full text view - ClinicalTrials.gov. https://clin icaltrials.gov/ct2/show/NCT01355484?term $=$

NCT01355484\&rank=1 (2016). Accessed 25 Jan 2017.

99. ClinicalTrials.gov. Safety and efficacy of anamorelin $\mathrm{HCl}$ in patients with non-small cell lung cancer-cachexia (ROMANA 1) full text view - ClinicalTrials.gov. https://clinicaltrials.gov/ct2/ show/NCT01387269?term=NCT01387269\&rank=1 (2015). Accessed 25 Jan 2017.

100. ClinicalTrials.gov. Safety and efficacy of anamorelin $\mathrm{HCl}$ in patients with non-small cell lung cancer-cachexia (ROMANA 2) full text view - ClinicalTrials.gov. https://clinicaltrials.gov/ct2/ show/NCT01387282?term=NCT01387282\&rank=1 (2015). Accessed 25 Jan 2017.

101. Temel JS, Abernethy AP, Currow DC, Friend J, Duus EM, Yan $\mathrm{Y}$, et al. Anamorelin in patients with non-small-cell lung cancer and cachexia (ROMANA 1 and ROMANA 2): results from two randomised, double-blind, phase 3 trials. Lancet Oncol. 2016;17:519-31.

102. ClinicalTrials.gov. Anamorelin $\mathrm{HCl}$ in the treatment of nonsmall cell lung cancer-cachexia (NSCLC-C): an extension study (ROMANA 3) - full text view - ClinicalTrials.gov. https://clin icaltrials.gov/ct2/show/NCT01395914?term= NCT01395914\&rank=1 (2015). Accessed 25 Jan 2017.

103. Caccialanza R, Cereda E, Pinto C, Cotogni P, Farina G, Gavazzi $\mathrm{C}$, et al. Awareness and consideration of malnutrition among oncologists: insights from an exploratory survey. Nutrition. 2016;32:1028-32. 